\title{
Gastric emptying and orocaecal transit time of meals containing lactulose or inulin in men
}

\author{
Miriam Clegg and Amir Shafat* \\ Department of Physical Education and Sport Sciences, University of Limerick, Limerick, Republic of Ireland
}

(Received 5 January 2010 - Revised 17 February 2010 - Accepted 19 February 2010 - First published online 7 April 2010)

The $\mathrm{H}_{2}$ breath test is ideal for orocaecal transit time (OCTT) measurement, as it is non-invasive and inexpensive. Indigestible substrates added to a test meal are metabolised by the colonic bacteria, resulting in the production of $\mathrm{H}_{2}$ which is detected in end-exhalation breath. However, the substrates themselves can alter the transit times in the gastrointestinal tract. The aim of the present study is to compare OCTT and gastric emptying (GE) when lactulose in liquid (L-L), solid lactulose (L-S) and solid inulin (IN-S) are added to a test meal, and subsequently, to examine if inulin alters GE. Firstly, ten male volunteers were tested on three occasions. Volunteers ate a pancake breakfast containing $100 \mathrm{mg}$ of ${ }^{13} \mathrm{C}$-octanoic acid and either $12 \mathrm{~g}$ of L-L, $12 \mathrm{~g}$ of L-S or $12 \mathrm{~g}$ of IN-S in a randomised order. Secondly, seven male volunteers were tested twice with meals containing either $12 \mathrm{~g}$ of IN-S or no substrate (NO-S). L-L induced the shortest OCTT (85.3 (SD 42.8) min) compared with L-S (162.4 (SD 62.6) min) and inulin (292.4 (SD 66.7) min; $P=0 \cdot 007$ ). GE half-time and lag phase (L-L: 61 (SD 9); L-S: 57 (SD 10); IN-S: 52 (SD 10) min; $P=0 \cdot 005)$ were also affected, with L-L being the slowest. Thirdly, inulin reduced GE lag and latency phases $(P<0 \cdot 05)$ compared with NO-S. Lactulose accelerates OCTT but delays GE compared with inulin. Inulin accelerates the onset of stomach emptying, but it has no effect on GE half-time. For these reasons, inulin is the preferred substrate for the $\mathrm{H}_{2}$ breath test.

Gastric emptying: Inulin: Lactulose: Orocaecal transit time

The $\mathrm{H}_{2}$ breath test is commonly used for diagnostic purposes and research ${ }^{(1)}$. In the clinical setting, $\mathrm{H}_{2}$ breath test is used to establish small intestinal overgrowth or lactase deficiency; in this instance, it was used to measure the time from when food is eaten till it reaches the large intestine or orocaecal transit time $(\mathrm{OCTT})^{(2)}$. Certain indigestible substances are metabolised by the colonic bacteria on reaching the caecum. $\mathrm{H}_{2}$, as well as methane, $\mathrm{CO}_{2}$ and other gases are produced. These diffuse into the bloodstream and into the alveoli where they can be detected in end-exhalation breath. The $\mathrm{H}_{2}$ breath test is ideal for the measurement of OCTT, as it is non-invasive, inexpensive and easy to perform ${ }^{(3)}$.

One substance that has been used widely in the $\mathrm{H}_{2}$ breath test to detect OCTT is the semi-synthetic disaccharide lactulose made up of fructose and galactose. Ternent et al. ${ }^{(4)}$ concluded from their research that the cost of lactulose $\mathrm{H}_{2}$ breath tests is $20 \%$ of the cost of scintigrams, yet they yield mouth to pouch transit results that correlate with accurate scintigraphs when a significant alveolar $\mathrm{H}_{2}$ peak is produced. However, lactulose is repeatedly criticised ${ }^{(5-8)}$ as it is primarily used clinically in the treatment of constipation, and has been shown to have a dose-dependent accelerating effect on $\mathrm{OCTT}^{(2)}$. In the small intestine, lactulose, which travels through the gastrointestinal tract undigested and unabsorbed, produces a surplus of molecules in the small intestine, inducing an osmotic effect, drawing fluid into the intestinal lumen, swelling the contents and stimulating intestinal peristalsis. Similarly, in the large intestine, lactulose is broken down by the colonic bacteria into low molecular organic acids. This leads to a lowering in $\mathrm{pH}$ in the colonic lumen and, again, fluids travel into the intestine, causing acceleration in intestinal transit. In essence, the lactulose substrate accelerates the time span, which it is believed to measure. In contrast, however, lactulose has been proven to slow gastric emptying $(\mathrm{GE})^{(7)}$. This supports the research by Read et al. ${ }^{(9)}$ that changes in small bowel transit time occur independently of changes in GE.

Inulin is a natural food ingredient commonly found in dietary foods. It has been estimated that Americans consume an average of $1-4 \mathrm{~g}$ of inulin and oligofructose per day, and Europeans consume approximately $3-10 \mathrm{~g} / \mathrm{d}^{(10)}$. Inulin and oligofructose are present as plant storage carbohydrates in a number of vegetables and plants including bananas, onion, garlic, wheat and chicory. Inulin has an average degree of polymerisation of $10-12$ and a distribution of molecules with chain lengths ranging from 2 to 60 units $^{(11)}$. High performance (HP) inulin (raftiline/inulin) is manufactured to remove the shorter chain molecules, so it has an average degree of polymerisation of 25 and a molecular distribution ranging from 11 to 60 . The structure of inulin is that of a polydisperse $\beta(2 \rightarrow 1)$ fructan. The fructose units in this mixture consist of linear fructose polymers and oligomers, each

Abbreviations: GE, gastric emptying; HP, high performance; IN-S, solid inulin; L-L, lactulose in liquid; L-S, solid lactulose; OCTT, orocaecal transit time. *Corresponding author: Dr Amir Shafat, fax +353 61 202814, email amir.shafat@ul.ie 
linked by $\beta(2 \rightarrow 1)$ bonds. A glucose molecule resides at the end of each fructose chain and is joined by an $\alpha(1 \rightarrow 2)$ bond, as in sucrose ${ }^{(11)}$. These linkages prevent inulin from being digested and absorbed like normal carbohydrates, resulting in a low energetic value. Inulin is also completely fermented by colonic microflora, leading to the production of $\mathrm{H}_{2}$. Geboes et al. ${ }^{(12)}$ state that 'Inulin is an ideal substrate for a $\mathrm{H}_{2}$ breath test to measure the orocaecal transit time.' They found that the OCTT correlated best with lactose ${ }^{13} \mathrm{C}$-ureide OCTT when HP raftiline was used, and that there was no proportional bias between the two techniques.

The effect of the addition of substrates for the measurement of OCTT in either solid or liquid form and its subsequent effect on GE are unclear. Studies examining OCTT using the $\mathrm{H}_{2}$ breath test have added the substrate primarily in the liquid form ${ }^{(6-8)}$. To be physiologically and nutritionally relevant, it is important to add the substrate to the appropriate portion of the meal. However, human subjects eat the majority of energy-rich foods in the solid state ${ }^{(13)}$. It is unclear if adding substrates to the solid or liquid phases of the meal will affect OCTT and GE.

The aim of the following two experiments was: (1) to determine if inulin accelerates GE compared with a control meal with no substrate; (2) to compare GE and OCTT of meals containing either inulin or lactulose; (3) to compare differences in GE and OCTT of identical test meals containing the substrate in either the liquid or solid section of the test meal.

\section{Experimental methods}

The present study consisted of two parts.

\section{Volunteers}

For part 1, ten apparently healthy male volunteers (25.1 (SD 2.7) years, 1.79 (SD 0.04) m, 78.3 (SD 6.0) kg, all data are expressed as means and standard deviations) participated in the study, which was approved by the Local Research Ethics Committee. For part 2, seven apparently healthy male volunteers (26.4 (SD 3.6) years, 1.79 (SD 0.05) m, $80.6($ SD 7.6) kg) participated in the study. All volunteers were screened to ensure that they had no history of gastrointestinal complaints, were not on medication that would alter gastrointestinal transit and had no intolerance to lactulose or were suffering from galactosaemia. Volunteers were all non-smokers, and were asked to refrain from consuming alcohol for $24 \mathrm{~h}$ before all the tests.

\section{Procedure}

Volunteers were tested on three occasions in part 1 and on two occasions in part 2. Before the first test session, they were asked to record their diet for a $24 \mathrm{~h}$ period using a weighed food diary. The food diary was repeated before the following test sessions, and there was an interval of a minimum of $5 \mathrm{~d}$ between each test day. To prevent prolonged intestinal $\mathrm{H}_{2}$ production due to the presence of non-absorbable or slowly fermentable material in the colon, volunteers were instructed to consume a low carbohydrate dinner the night before the test, and were given guidelines about how they could achieve this.
Volunteers visited the laboratory following a $12 \mathrm{~h}$ overnight fast. On arrival to the laboratory, baseline breath samples were taken. A pancake meal was administered, and the volunteers were given $15 \mathrm{~min}$ to consume it. If the meal was finished before the allocated $15 \mathrm{~min}$, the clock was reset to zero and all the subsequent measurements were taken from that time onwards.

\section{Test meal}

The test meal consisted of five small plain pancakes containing $140 \mathrm{ml}$ whole milk, one egg, $5 \mathrm{ml}$ olive oil, $50 \mathrm{~g}$ plain flour, $50 \mathrm{~g}$ raspberry jam and $200 \mathrm{ml}$ water. The test meal had an energy content of $2138 \mathrm{~kJ}(511 \mathrm{kcal})$, and consisted of $16 \mathrm{~g}$ fat, $17.4 \mathrm{~g}$ protein and $80 \mathrm{~g}$ carbohydrate. In part 1 , all the three pancake meals were supplemented with $100 \mathrm{mg}$ ${ }^{13} \mathrm{C}$-octanoic acid (Eurisotop, Saint-Aubin, France) and with either $12 \mathrm{~g}$ solid lactulose (L-S, Duphalac dry; Solvay Pharma, Brussels, Belgium) or $12 \mathrm{~g}$ solid inulin (IN-S, Raftiline HP; Orafti, Belgium) in the pancakes or $12 \mathrm{~g}$ lactulose in liquid (L-L, Duphalac syrup; Solvay Pharma) dissolved in water. In part 2, the pancakes were supplemented with $100 \mathrm{mg}{ }^{13} \mathrm{C}$-octanoic acid and either $12 \mathrm{~g}$ IN-S or no substrate.

The volunteers drank the water after finishing the pancake portion of the meal. Raftiline HP was selected based on the findings by Geboes et al. ${ }^{(12)}$. The meals were administered in a single-blind randomised order.

Both GE, the time it takes for the food to empty from the stomach, and OCTT, the time from when the food is eaten till it reaches the large intestine, were measured by analysis of exhaled breath ${ }^{(14)}$. This proposed method has been advocated previously for use in the diagnosis of gastrointestinal disorders.

\section{Orocaecal transit time}

The $\mathrm{H}_{2}$ breath test was used to measure OCTT ${ }^{(2)}$. Breath $\mathrm{H}_{2}$ was tested every $10 \mathrm{~min}$ using $\mathrm{H}_{2}$ meter (Micro $\mathrm{H}_{2}$; Micro Medical, Chatham, UK) for up to $8 \mathrm{~h}$. OCTT was defined as a consecutive increase in breath $\mathrm{H}_{2}$ over three consecutive readings of at least a cumulative 10 parts per million. Volunteers were free to leave after $6 \mathrm{~h}$ if OCTT had been reached; if OCTT was not reached at $8 \mathrm{~h}$, the test was terminated regardless.

\section{Gastric emptying}

Breath samples were taken every $15 \mathrm{~min}$ until $6 \mathrm{~h}$ for the analysis of breath ${ }^{13} \mathrm{CO}_{2}$. Samples were collected by blowing gently into a $10 \mathrm{ml}$ Exetainer $^{\circledR}$ (Labco, High Wycombe, Bucks, UK) with a drinking straw, and replacing the cap just before the end of exhalation. Breath samples were analysed using isotope ratio MS (ABCA, SerCon Limited, Crewe, Chesire, UK), and the results were expressed relative to Pee Dee Belemnite, an international standard for known ${ }^{13} \mathrm{C}$ composition. ${ }^{13} \mathrm{CO}_{2}$ values were expressed as the excess amount in the breath above baseline, and were converted into moles. Data are displayed as the percentage of ${ }^{13} \mathrm{CO}_{2}$ dose recovered per hour and cumulative percentage of ${ }^{13} \mathrm{CO}_{2}$ recovered over time. $\mathrm{CO}_{2}$ production was assumed to be $300 \mathrm{mmol} / \mathrm{m}^{2}$ body surface area per hour. Body surface 


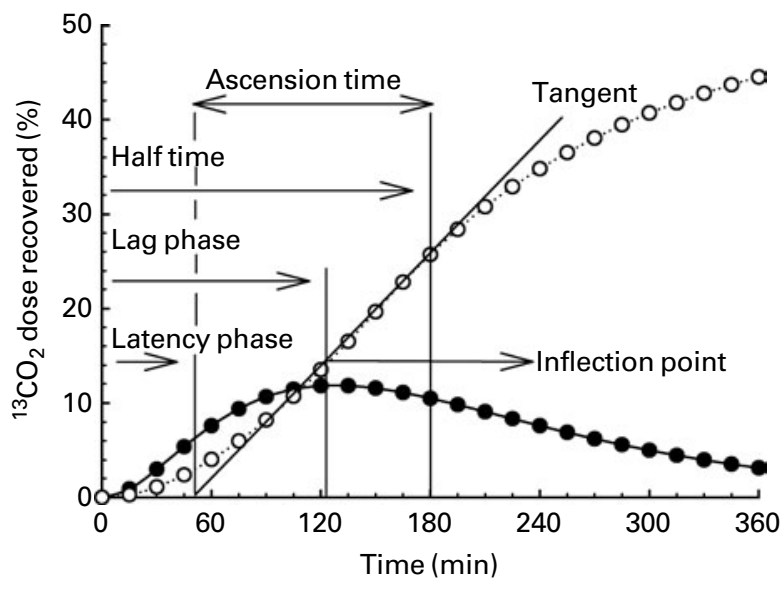

Fig. 1. Graph, adapted from Clegg \& Shafat ${ }^{(25)}$, illustrating the percentage dose recovered per $\mathrm{h}$ and cumulative percentage dose recovered of the modelled ${ }^{13} \mathrm{CO}_{2}$ over time. $\rightarrow$ and $\leftrightarrow$, Various time points of relevance for analysis of gastric emptying; $-\bullet-$, percentage dose recovered per $\mathrm{h} ; \cdots \circ \cdots$ cumulative percentage dose recovered.

area was calculated using a validated weight-height formula $^{(15)}$. This was then fitted to a GE model developed by Ghoos et al. ${ }^{(16)}$. For all the data, $r^{2}$ coefficient between the modelled and raw data was calculated and $r^{2}>0.90$. From this model, several parameters were measured (Fig. 1). GE half-time $\left(T_{\text {half }}\right)$ is the time taken for $50 \%$ of the total cumulative dose of ${ }^{13} \mathrm{CO}_{2}$ dose to be excreted. Lag phase $\left(T_{\text {lag }}\right)$ is the time taken to maximal excretion rate, which is the same as the time of the inflection point of the tangent to the cumulative ${ }^{13} \mathrm{CO}_{2}$ excretion curve. The latency phase $\left(T_{\text {lat }}\right)^{(17)}$ is the point of intersection of the tangent at the inflection point of the ${ }^{13} \mathrm{CO}_{2}$ excretion curve representing an initial delay in the excretion curve. Ascension time $\left(T_{\text {asc }}\right)^{(17)}$ is the time course between the latency phase and the half excretion time, representing a period of high ${ }^{13} \mathrm{CO}_{2}$ excretion rates. Scintigraphic equivalent values of lag phase $\left(T_{\text {lags }}\right)$ and half-time $\left(T_{\text {halfs }}\right)$ were also calculated using the formulas derived by Ghoos et al. ${ }^{(16)}$. From the raw (unmodelled) data, the total percentage dose recovered was examined, as were the peak in percentage dose recovered per hour and the time at which this occurred.

\section{Statistical analysis}

All data were tested for normal distribution. In part 1, data were normally distributed; hence, statistical significance $(P<0 \cdot 05)$ was examined with SPSS (version 15.0; SPSS, Inc., Cary, NC, USA) using a repeated-measures ANOVA with the three substrates as within-subject factors. Post hoc analysis was done by pairwise comparison. In part 2, statistical significance $(P<0.05)$ was examined with SPSS (version 15.0) using a Wilcoxon signed rank test because data were not normally distributed.

\section{Results}

Part 1

Orocaecal transit time. An overall effect of the meals $(P=0.007, n 7)$ on OCTT was observed. Three volunteers,

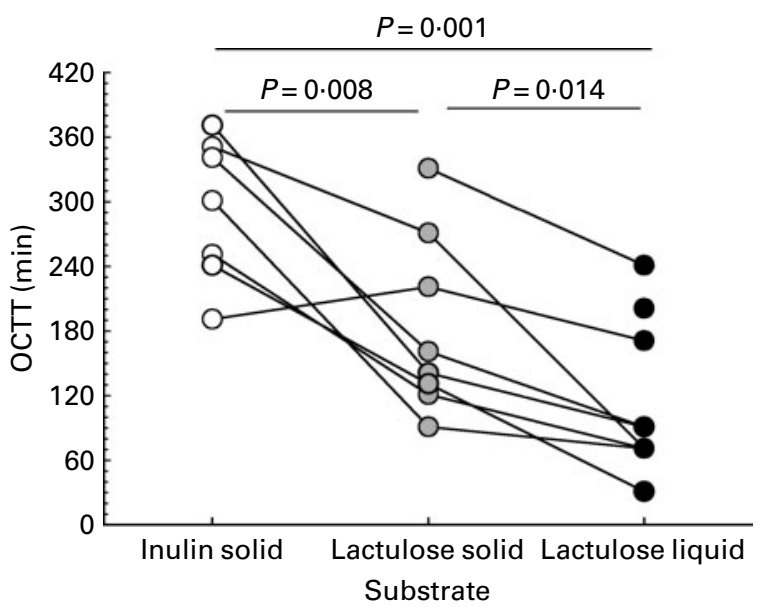

Fig. 2. Orocaecal transit time (OCTT) of all the volunteers $(n 9)$ for the three meals: lactulose in liquid; solid lactulose; solid inulin. Lactulose in liquid had the average shortest emptying time of 85 (SD 43) min compared with 162 (SD 63) min for lactulose solid and 292 (SD 67) min for inulin solid.

however, did not show an increase in breath $\mathrm{H}_{2}$ after the consumption of IN-S. One of these was a non-responder to all the three tests; another volunteer also showed no increase for L-S. As can be seen in Fig. 2, the shortest OCTT of 85.3 (SD 42.8) min was for L-L; L-S had a longer transit time of 162.4 (SD 62.6) min, while IN-S had the longest transit time of 292.4 (SD 66.7) min. Differences existed between all the three substrates, between IN-S and L-S $(P=0 \cdot 008)$, between L-S and L-L $(P=0 \cdot 014)$, and between IN-S and L-L $(P=0 \cdot 001)$. Fig. 3 demonstrates the breath $\mathrm{H}_{2}$ curves for volunteer 4 for the three meals L-L, L-S and IN-S over the $6-8 \mathrm{~h}$ postprandial period. These represent the typical $\mathrm{H}_{2}$ curves observed throughout.

Gastric emptying. Lactulose delayed GE compared with inulin. There were significant overall changes in $T_{\text {halfs }}$ $(P=0.017), T_{\text {lagS }}(P=0.005), T_{\text {lat }}(P=0.004), T_{\text {half }}(P=0.017)$, $T_{\text {lag }}(P=0 \cdot 002)$, and $T_{\text {peak }}(P=0 \cdot 020)$, but not in $T_{\text {asc }}(P=0 \cdot 112)$,

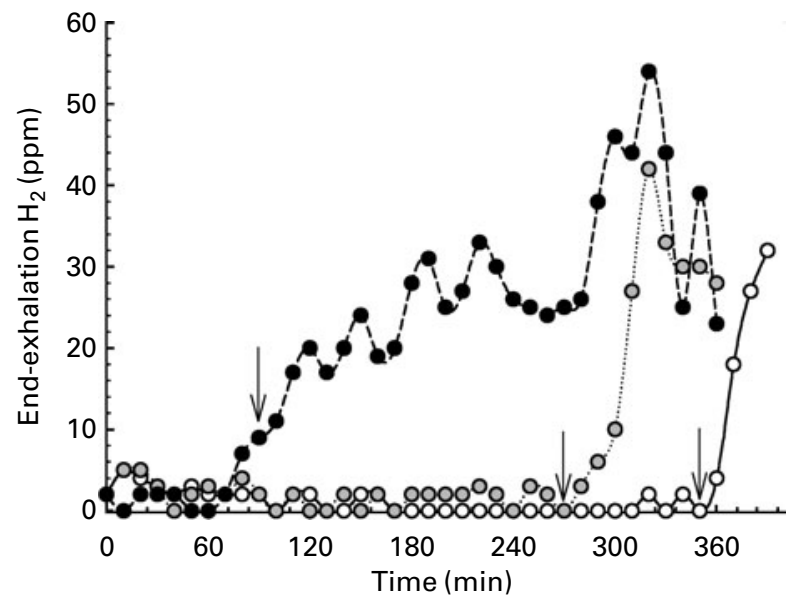

Fig. 3. Representation of the typical (volunteer 4) breath hydrogen curves with respect to time for each of the three meals: lactulose in liquid; solid lactulose; solid inulin. Transit times for lactulose liquid, lactulose solid and inulin solid are 90, 270 and $350 \mathrm{~min}$, respectively. $\downarrow$, Orocaecal transit time; - - -, inulin; -- ○--, lactulose solid; -----, lactulose in liquid; ppm, parts per million. 
Table 1. Gastric emptying parameters given in minutes for solid inulin, solid lactulose and liquid lactulose for test 1 (Mean values and standard deviations, $n 10$ )

\begin{tabular}{|c|c|c|c|c|c|c|}
\hline \multirow[b]{2}{*}{ Time (min) } & \multicolumn{2}{|c|}{ Solid inulin } & \multicolumn{2}{|c|}{ Solid lactulose } & \multicolumn{2}{|c|}{ Liquid lactulose } \\
\hline & Mean & SD & Mean & SD & Mean & SD \\
\hline$T_{\text {half }}$ & 186 & 13 & $203^{\star *}$ & 20 & $203^{*}$ & 22 \\
\hline$T_{\text {lag }}$ & 131 & 17 & $143^{\star \star}$ & 20 & $149^{\star \star}$ & 18 \\
\hline$T_{\text {asc }}$ & 132 & 13 & $144^{\star *}$ & 16 & $138^{* *} \dagger$ & 19 \\
\hline$T_{\text {lat }}$ & 54 & 15 & $59^{*}$ & 14 & 65 & 12 \\
\hline$T_{\text {halfs }}$ & 107 & 12 & $122^{\star \star}$ & 18 & $123^{\star \star}$ & 20 \\
\hline$T_{\text {lags }}$ & 52 & 10 & $57^{\star \star}$ & 10 & $61^{\star *}$ & 9 \\
\hline Total dose recovered (\%) & $47 \cdot 27$ & 2.94 & 48.26 & 4.32 & $49 \cdot 24$ & 3.04 \\
\hline Peak dose recovered (\%) & 13.05 & $0 \cdot 76$ & $13 \cdot 14$ & 1.55 & $13 \cdot 75^{\star}$ & $1 \cdot 11$ \\
\hline$T_{\text {peak }}$ & 143 & 25 & $162^{\star *}$ & 20 & $161^{*}$ & 26 \\
\hline
\end{tabular}

Mean values were significantly different when compared with that of inulin: ${ }^{\star} P \leq 0.05,{ }^{\star \star} P \leq 0.01$. † Mean values were significantly different when compared with that of solid lactulose $(P \leq 0.01)$.

peak in percentage dose recovered $(P=0.090)$ or total dose recovered $(P=0.485)$ between all the three meals ( $n$ 10). Comparisons between individual substrates for these parameters are given in Table 1. Overall, all measures of GE rates were 5-18 min faster in meals containing inulin than in those containing lactulose. The accelerated GE rates in lactulose-labelled meals were evident in both liquid and solid conditions. However, GE rates were similar for lactulose added to the water and pancake portions of the meal, with one exception (ascension time). Fig. 4 illustrates the GE percentage dose recovered for volunteer 4 for the three meals $\mathrm{L}-\mathrm{L}, \mathrm{L}-\mathrm{S}$ and IN-S over the $6 \mathrm{~h}$.

\section{Part 2}

Gastric emptying. There were significant differences in GE $T_{\text {lag }}\left(P=0.028\right.$; Fig. 5), $T_{\text {lat }}(P=0.028)$ and $T_{\text {lags }}(P=0.028)$ between the two meals, with the IN-S meal having 6-10 min shorter emptying time than the no substrate meal as can be seen in Table 2. There were no differences in the other parameters of GE, and $T_{\text {half }}, T_{\text {halfs }}$ and $T_{\text {peak }}$ had exactly the same average emptying times.

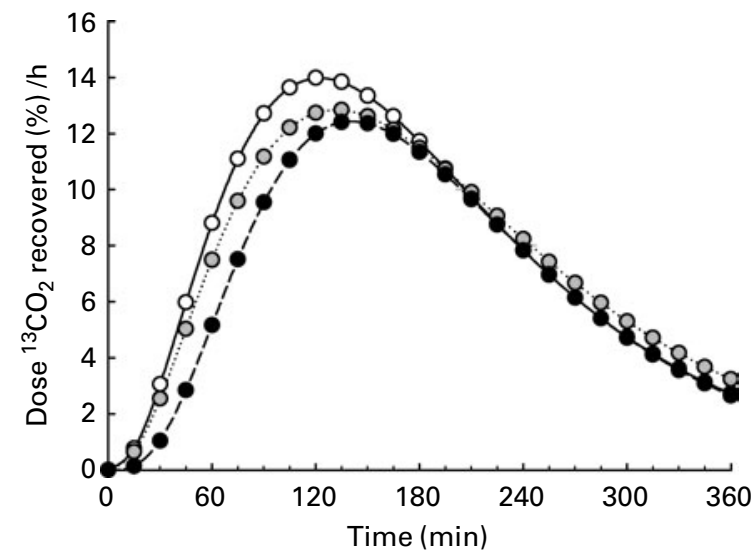

Fig. 4. Percentage dose recovered curves for one volunteer for each of the three substrate meals: lactulose in liquid (--0--); solid lactulose (--৩--); solid inulin (-O-).

\section{Discussion}

The two lactulose meals (L-L and L-S) had a shorter OCTT than the IN-S meal. This supports the work done by Geboes et $a l^{(12)}$ demonstrating that lactulose accelerates transit of food through the gastrointestinal tract in comparison to inulin. Miller et al. ${ }^{(7)}$ similarly found that lactulose decreased transit time compared with gastroenterocolonic scintigraphy; however, a strong correlation existed ( $r$ 0.95) between the two. A possible explanation for this is the osmotic effect of lactulose. As chyme travels into the small intestine, the nutrient content of it is absorbed. As lactulose is unabsorbable, it progresses aborally. Lactulose is a relatively small molecule (a disaccharide) compared with inulin, which has at least a tenfold higher degree of polymerisation. In this way, water travels by osmosis into the small intestine, stimulates peristalsis and allows the contents of the distal small intestine to travel faster $^{(7)}$. This theory is further supported by findings ${ }^{(8)}$ that transit time decreased with increasing doses of lactulose. OCTT not only correlates best with ${ }^{13} \mathrm{C}$-ureide OCTT (353 (285-375) min; mean (interquartile range)) when raftiline HP (338 (300-383) min; mean (interquartile range)) is used, but there is also no proportional bias between the two methods ${ }^{(12)}$.

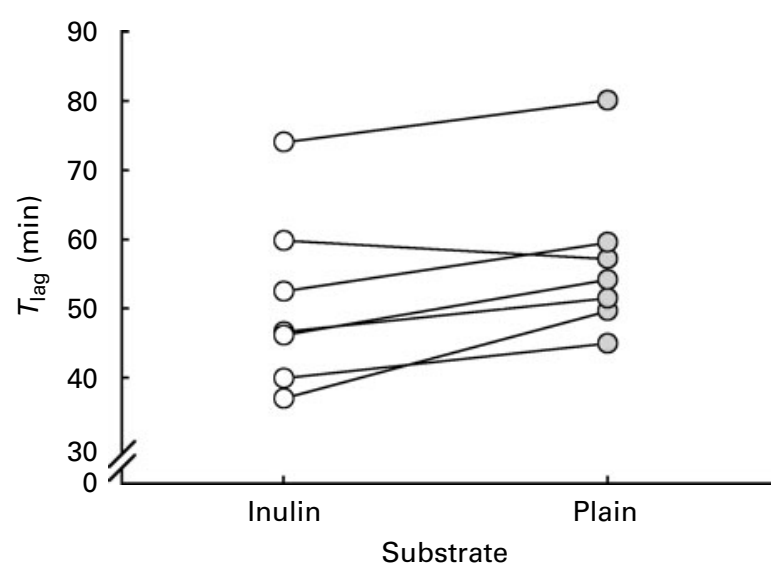

Fig. 5. Gastric emptying lag phase $\left(T_{\text {lag }}\right)$ in minutes $(n 7)$ for pancake meal containing solid inulin and no inulin (plain). 
Table 2. Gastric emptying parameters given in minutes for solid inulin and plain for test 2

(Mean values and standard deviations, $n$ 7)

\begin{tabular}{lccccc}
\hline & \multicolumn{2}{c}{ Inulin } & & \multicolumn{2}{c}{ Plain } \\
\cline { 2 - 3 } \cline { 6 - 7 } Time $(\min )$ & Mean & SD & & Mean & SD \\
\hline$T_{\text {half }}$ & 196 & 26 & & 196 & 30 \\
$T_{\text {lag }}$ & 133 & 26 & & $143^{\star}$ & 25 \\
$T_{\text {asc }}$ & 145 & 13 & & 135 & 19 \\
$T_{\text {lat }}$ & 51 & 17 & & $61^{*}$ & 15 \\
$T_{\text {halfS }}$ & 116 & 23 & & 116 & 27 \\
$T_{\text {lags }}$ & 51 & 13 & & $57^{\star}$ & 11 \\
Total dose recovered (\%) & $45 \cdot 93$ & 4.43 & & 43.98 & 7.31 \\
Peak dose recovered (\%) & 12.48 & 1.41 & & $12 \cdot 30$ & 1.79 \\
$T_{\text {peak }}$ & 146 & 30 & & 146 & 24 \\
\hline
\end{tabular}

${ }^{*}$ Mean values were significantly different when compared with inulin $(P \leq 0.05)$.

In part one of the present study there was one individual who was a hydrogen non-responder. It has been reported ${ }^{(18)}$ that $20 \%$ of the individuals are non- $\mathrm{H}_{2}$ producers. Similarly, high figures have been found by other researchers such as seven out of twenty-one subjects ${ }^{(4)}$. Other researchers found lower numbers of non-responders such as two out of fortytwo volunteers ${ }^{(2)}$ and one non-responder out of fifty-two volunteers ${ }^{(19)}$. The two other individuals in the present study who did not show any increase in breath $\mathrm{H}_{2}$ after the consumption of inulin had longer transit times for the other two substrates, L-S and L-L, suggesting that OCTT was reached after $8 \mathrm{~h}$ of measurement that was done postprandially. Other studies have taken breath measurements for up to $10 \mathrm{~h}^{(12)}$; however, in a clinical setting or with larger test meals, this may not be practical.

L-L had a shorter OCTT than L-S. Lactulose syrup was added to the liquid portion of the meal, and solid (powder) lactulose was added to the solid pancake portion of the meal. The $\mathrm{H}_{2}$ breath test measures the time until the head of the meal reaches the caecum of the large intestine. This demonstrates that the OCTT of a liquid is shorter than that of a solid. Although obvious, this is missing from the current body of literature that clearly underlines differences in GE of liquids and solids ${ }^{(20)}$.

It was first highlighted by Castellani et al. ${ }^{(21)}$ and later by Brighenti et al. ${ }^{(22)}$ that inulin may be a better probe for the $\mathrm{H}_{2}$ breath test. The present study showed differences in GE when equal amounts of inulin and lactulose were added to the test meals, with lactulose delaying GE in comparison to inulin. The slower GE rates were even significant when a solid test meal was used, which was unconfirmed by Geboes et al. ${ }^{(12)}$. Several suggestions have been made to explain these changes, such as increased duodenal contraction associated with lactulose meals slows $\mathrm{GE}^{(7)}$. The present results show differences in $T_{\text {lat }}$ and $T_{\text {lag }}$ between the meals. These two time periods represent the first portion of the meal that is emptied from the stomach. If lactulose caused a feedback mechanism based on duodenal motility that slowed GE, then $T_{\text {asc }}$ and $T_{\text {half }}$ would primarily have been affected, as opposed to the time periods at the start of emptying. For the same reason, increased delivery of nutrients into the duodenum cannot be the cause of delayed initial $\mathrm{GE}^{(22)}$. Other explanations, such as the increased osmolality of lactulose in the stomach ${ }^{(23)}$, are more likely. Finally, another suggestion has been made that lactulose increases the viscosity of the meal, while inulin does not ${ }^{(24)}$. The increased viscosity due to lactulose is greater for liquid meals whose initial viscosity is lower, and thus GE is altered more by the addition of gelling agents $^{(12)}$. This may explain the differences in GE of the solids of L-L and L-S, when equal amounts of lactulose just in different states were added to the test meals.

The second part of these experiments is the first to show that IN-S accelerated GE for time points $\mathrm{GE}_{\text {lag }}$ and $\mathrm{GE}_{\mathrm{lat}}$; both these points represent the start of emptying of the meal from the stomach. It can be seen in Fig. 5 that this difference between the two meals was evident in six out of seven volunteers. However, the $\mathrm{GE}_{\text {half }}$ and $T_{\text {peak }}$ have exactly the same average times for the two meals. One possibility is that this acceleration in the emptying of IN-S is caused by the difference in meal weight due to the addition of inulin; as this is only $12 \mathrm{~g}$, it is unlikely. Alternatively, it may be due to the large molecular size of inulin $\mathrm{HP}^{(11)}$ which has an alternate effect to lactulose and decreases the osmolarity of the meal, or perhaps it is due to both these reasons. It does make us question if the delay we observe in GE of lactulose is absolute or is it just a relative delay compared with inulin? However, the difference for lactulose was across the board for almost all the measurements of $\mathrm{GE}$, and the average differences in time were approximately double than those in the IN-S/no substrate comparison.

This is the first study to show significant differences in GE between lactulose and inulin, and to examine the effects of inulin on GE. Based on previous literature, it has been demonstrated that lactulose accelerates OCTT and has tendencies to delay GE, but that inulin does not accelerate OCTT $^{(12)}$. Data presented here demonstrate that inulin accelerates GE at the start of a meal, but not to the extent that lactulose delays GE. Taken together, it can be concluded that inulin is a better substrate for the $\mathrm{H}_{2}$ breath test, though its use in a clinical setting may be compromised by its long transit time.

\section{Acknowledgements}

The authors gratefully acknowledge Dr Marion Rowland and Mr Mark Dobson for their generous help in setting up the isotope ratio mass spectrometer for the present study. The authors gratefully acknowledge the support of the Irish Research Council for Science, Engineering and Technology. Inulin HP was a generous contribution from O'Brien's Ingredients, Ireland (representing BENEO-Orafti), and lactulose was generously donated by Solvay, Belgium. There are no conflicts of interest in the present paper. Both M. C. and A. S. contributed to the manuscript by establishing the study design, collecting the data, analysing the data and writing the manuscript.

\section{References}

1. Simren M \& Stotzer PO (2006) Use and abuse of hydrogen breath tests. Gut 55, 297-303.

2. Bond JH Jr, Levitt MD \& Prentiss R (1975) Investigation of small bowel transit time in man utilizing pulmonary hydrogen $\left(\mathrm{H}_{2}\right)$ measurements. J Lab Clin Med 85, 546-555.

3. Di Stefano M, Miceli E, Malservisi S, et al. (2003) Mixing of the intestinal content and variations of fermentation capacity do not affect the results of hydrogen breath test. Am J Gastroenterol 98 , 1584-1587. 
4. Ternent CA, Thorson AG, Blatchford GJ, et al. (2001) Mouth to pouch transit after restorative proctocolectomy: hydrogen breath analysis correlates with scintigraphy. Am J Gastroenterol 96, $1460-1463$.

5. Korth H, Muller I, Erckenbrecht JF, et al. (1984) Breath hydrogen as a test for gastrointestinal transit. Hepatogastroenterology 31, 282-284.

6. Ladas SD, Latoufis C, Giannopoulou H, et al. (1989) Reproducible lactulose hydrogen breath test as a measure of mouth-to-cecum transit time. Dig Dis Sci 34, 919-924.

7. Miller MA, Parkman HP, Urbain JL, et al. (1997) Comparison of scintigraphy and lactulose breath hydrogen test for assessment of orocecal transit: lactulose accelerates small bowel transit. Dig Dis Sci 42, 10-18.

8. La Brooy SJ, Male PJ, Beavis AK, et al. (1983) Assessment of the reproducibility of the lactulose $\mathrm{H}_{2}$ breath test as a measure of mouth to caecum transit time. Gut 24, 893-896.

9. Read NW, Cammack J, Edwards C, et al. (1982) Is the transit time of a meal through the small intestine related to the rate at which it leaves the stomach? Gut 23, 824-828.

10. van Loo J, Coussement P, de Leenheer L, et al. (1995) On the presence of inulin and oligofructose as natural ingredients in the western diet. Crit Rev Food Sci Nutr 35, 525-552.

11. Niness KR (1999) Inulin and oligofructose: what are they? J Nutr 129, Suppl. 7, 1402S-1406S.

12. Geboes KP, Luypaerts A, Rutgeerts P, et al. (2003) Inulin is an ideal substrate for a hydrogen breath test to measure the orocaecal transit time. Aliment Pharmacol Ther 18, 721-729.

13. Ledikwe JH, Blanck HM, Khan LK, et al. (2005) Dietary energy density determined by eight calculation methods in a nationally representative United States population. J Nutr 135, 273-278.

14. Urita Y, Hike K, Torii N, et al. (2002) Efficacy of lactulose plus ${ }^{13} \mathrm{C}$-acetate breath test in the diagnosis of gastrointestinal motility disorders. J Gastroenterol 37, 442-448.
15. Haycock GB, Schwartz GJ \& Wisotsky DH (1978) Geometric method for measuring body surface area: a height-weight formula validated in infants, children, and adults. J Pediatr 93, 62-66.

16. Ghoos YF, Maes BD, Geypens BJ, et al. (1993) Measurement of gastric emptying rate of solids by means of a carbon-labeled octanoic acid breath test. Gastroenterology 104, 1640-1647.

17. Schommartz B, Ziegler D \& Schadewaldt P (1998) Significance of diagnostic parameters in $\left[{ }^{13} \mathrm{C}\right]$-octanoic acid gastric emptying breath tests. Isotopes Environ Health Stud 34, 135-143.

18. Gilat T, Ben Hur H, Gelman-Malachi E, et al. (1978) Alterations of the colonic flora and their effect on the hydrogen breath test. Gut 19, 602-605.

19. Metz G, Jenkins DJ \& Blendis LM (1976) Proceedings: lactulose-hydrogen $\left(\mathrm{H}_{2}\right)$ breath test in health and disease. Gut 17, 397-398.

20. Siegel JA, Urbain JL, Adler LP, et al. (1988) Biphasic nature of gastric emptying. Gut 29, 85-89.

21. Castellani G, Benini L \& Brigherti F (1994) Inulin is a better probe than lactulose for the measurement of orocaecal transit time. Gut 35, Suppl. 5, 19 (abstract w76).

22. Brighenti F, Casiraghi MC, Pellegrini N, et al. (1995) Comparison of lactulose and inulin as reference standard for the study of resistant starch fermentation using hydrogen breath test. Ital J Gastroenterol 27, 122-128.

23. Vist GE \& Maughan RJ (1995) The effect of osmolality and carbohydrate content on the rate of gastric emptying of liquids in man. $J$ Physiol Pt 2, 486, 523-531.

24. Schneeman BO (1999) Fiber, inulin and oligofructose: similarities and differences. J Nutr 129, Suppl. 7, 1424S-1427S.

25. Clegg ME \& Shafat A (2010) Energy and macronutrient composition of breakfast affect gastric emptying of lunch and subsequent food intake, satiety and satiation. Appetite (epublication ahead of print version 16 February 2010). 